\title{
Review Article \\ The Skin as an Early Expression of Malignancies in the Neonatal Age: A Review of the Literature and a Case Series
}

\author{
Vito Mondì, Fiammetta Piersigilli, Guglielmo Salvatori, and Cinzia Auriti \\ Department of Medical and Surgical Neonatology, Bambino Gesù Children's Hospital, Piazza S. Onofrio 4, 00165 Rome, Italy \\ Correspondence should be addressed to Cinzia Auriti; cinzia.auriti@opbg.net
}

Received 11 September 2015; Revised 15 November 2015; Accepted 29 November 2015

Academic Editor: Razvigor Darlenski

Copyright ( 2015 Vito Mondi et al. This is an open access article distributed under the Creative Commons Attribution License, which permits unrestricted use, distribution, and reproduction in any medium, provided the original work is properly cited.

\begin{abstract}
Skin lesions are a frequent finding in childhood, from infancy throughout adolescence. They can arise from many conditions, including infections and inflammation. Most neonatal rashes are benign and self-limiting and require no treatment. Other conditions may be an expression of malignancy or may be a marker for other abnormalities, such as neural tube defects. Therefore, skin lesions require an extensive evaluation and close follow-up to ensure the best possible outcome. This paper briefly reviews the main tumor types presenting with cutaneous involvement in neonates, followed by the description of some patients admitted to our Neonatal Intensive Care Unit with an early skin expression of malignancies.
\end{abstract}

\section{Background}

Dermatological diseases in neonates are commonly benign and self-limiting, but they may also herald underlying systemic diseases that are potentially life threatening. Neonatal cancer is a relatively uncommon finding; in UK and USA, the incidence is approximately one in every $12,500-27,500$ live births [1], varying from 17 to 121 per million live births in reported series $[2,3]$. Neonatal cancer, though uncommon, can be already present at birth and a skin lesion can be its first sign. Many malignancies can present already at the first examination after birth as a "blueberry muffin" rash, characterized by localized or generalized reddish-blue papular nodules. In fact, besides congenital infections from the ToxoplasmaRubella-Cytomegalovirus-Herpes (TORCH) complex and severe haemolysis, many early onset malignancies may cause a similar clinical picture (Table 1 and Table 2) [4-9].

In this paper, we review the most frequent neonatal malignancies presenting in the neonate with predominant skin involvement.

\section{Leukemia}

The incidence of neonatal leukaemia, diagnosed in the first 28 days of life after birth, ranges from 1 to 5 million live births [10]. Leukaemia cutis is reported to be the initial presenting sign in $50 \%$ of neonates with leukemia [11, 12]. It is a broad term used to describe any cutaneous localisation of leukaemic cells in the skin, occurring in $25-64 \%$ of patients with neonatal acute leukaemia. In approximately $10 \%$ of the cases, neonates can present with leukaemia cutis, without bone marrow involvement, a condition termed aleukaemic leukaemia cutis $[10,12]$. The blueberry muffin rash can be the initial manifestation both of acute myeloid leukaemia (AML) and of acute lymphoblastic leukaemia (ALL). The pathophysiology underlying the migration of leukaemic cells in the skin is not yet understood and there is no evidence of a specific phenotype associated with cutaneous localization. It has been speculated that the chemokine, integrin, and other adhesion (ICAM-1) molecules may play a role in skin specific homing of T and B leukemic cells. CD56 (blast neural cell adhesion molecule) expressed on leukemic blasts has been associated with extramedullary disease in acute leukemia patients with $t(8 ; 21)$ [13]. Nevertheless, some genetic or chromosomal alterations are found in specific subtypes of leukaemia and have a role in conditioning the severity of the clinical course.

Rearrangement of the mixed lineage leukaemia (MLL) gene, which occurs in the 11q23 translocation, leads to aggressive acute leukaemia and may be present in both 
TABLE 1: Causes of the blueberry muffin rash.

\begin{tabular}{ll}
\hline $\begin{array}{l}\text { Congenital } \\
\text { infections }\end{array}$ & TORCH complex \\
\hline $\begin{array}{l}\text { Severe } \\
\text { haemolysis }\end{array}$ & $\begin{array}{l}\text { (i) ABO or Rhesus incompatibility } \\
\text { (ii) Hereditary spherocytosis }\end{array}$ \\
\hline Congenital & (i) Multiple hemangiomas of infancy \\
vascular lesions & (ii) Multifocal lymphangioendotheliomatosis \\
& $\begin{array}{l}\text { (iii) Blue rubber bleb nevus syndrome } \\
\text { (iv) Multiple glomangiomas }\end{array}$ \\
& (i) Leukemia \\
& (ii) Langerhans cell histiocytosis \\
Early onset & (iii) Disseminate neuroblastoma \\
malignancies & (iv) Rhabdoid tumor \\
& (v) Rhabdomyosarcoma \\
& (vi) Primitive neuroectodermal tumors \\
& (vii) Choriocarcinoma \\
& (viii) Myofibromatosis
\end{tabular}

AML and ALL [11]; it occurs in 34\% of this subgroup [14]. On the other hand, spontaneous remission can occur in a subset of neonates affected by AML M4 with $\mathrm{t}(8 ; 16)$ (p11;p13). Nevertheless, recurrence can occur in almost half of the cases in the first year of life [15].

In utero leukaemogenesis has been suspected because of the finding of high leukemic cell burdens at birth and from autopsies of stillborn infants with leukemia and because of the description of leukemia with identical karyotype abnormalities in monozygotic twins. An association between maternal exposure to multiple toxins and the development of neonatal leukaemia has been extensively explored and an increased risk related to maternal marijuana use and alcohol consumption has been demonstrated [16, 17]. Therefore, a maternal diet high in flavonoids is suspected to increase the risk of MLL-rearranged infant leukaemia [18].

Congenital leukemia has a higher mortality rate than any other form of congenital cancer; on the other hand, cases of spontaneous remission of AML have been described in patients with AML [19]. These considerations raise the dilemma of deciding when to treat or to wait in case of a neonate presenting with congenital leukemia.

2.1. Clinical Presentation. The clinical presentation of neonatal leukemia can be variable. Patients are likely to present with hyperleukocytosis (65\% of ALL patients and $49 \%$ of AML patients), hepatosplenomegaly (80\%), more often than enlarged spleen, central nervous system involvement (50\%), and lymphadenopathy (24\%). A severe complication of hyperleucocytosis is the leukostasis syndrome, in which white cell plugs are formed in the microvasculature, leading to cardiac failure and respiratory and neurological problems. Neurological symptoms may include somnolence and coma, papilloedema, retinal vein distension, and retinal haemorrhage. Respiratory symptoms may include tachypnoea, dyspnoea, hypoxia with pulmonary infiltrates, or respiratory failure [20, 21]. Furthermore, leukemia may manifest itself with anemia and bone pain because of extramedullary infiltration.

2.2. Skin Involvement. Skin involvement is frequently present already at birth with multiple randomly distributed subcutaneous nodules on the trunk and face, with bluish infiltrates on the whole body surface, similar to blueberry muffin eruption, although nodular lesions can be usually small and not bluish, and the infiltrate can be subcutaneous, not nodular and with a generalized distribution (Figure 1). The infiltrate exhibits no blanching response to palpation. In addition to the examination of the peripheral smear to evaluate the percentage of blast cells, thrombocytopenia or anemia, the bone marrow aspirate to perform cytogenetic analysis, a skin biopsy is also mandatory. In approximately $10 \%$ of cases of congenital leukemia cutis, cutaneous manifestations may be present in the setting of normal bone marrow and peripheral blood smear [22].

The histopathologic analysis of the lesions in leukemia cutis may reveal several different patterns of infiltration. Most commonly they appear as a dense diffuse dermal infiltrate of pleomorphic leukemic cells, observed in a linear array between collagen bundles in the reticular dermis. Alternatively, band-like as well as compact nodular infiltrates may be seen. These infiltrates rarely reach the epidermis and most cases show extension into the subcutis. The nuclei of these cells may range from markedly atypical folded or reniform nuclei to monomorphous and cytological bands. Determining the leukemic infiltrate subtype almost always requires staining for immunophenotypic markers and their association with cryptologic and cytogenetic data $[23,24]$.

\section{Transient Myeloproliferative Disorder}

Transient myeloproliferative disorder (TMD) is clonal proliferation of megakaryoblasts, typically occurring in newborns with Down syndrome (DS), with a range between $4 \%$ and $6 \%$. The first case was reported by Schunk and Lehman in 1954 [25]. Frequently, TMD disappears during the first 3 months of life, but after a period of normal marrow morphology and peripheral blood count recovery, a significant percentage of patients develop acute leukemia (most commonly AML) within the first 4 years of life. Because TMD appears to be restricted to patients with DS or trisomy 21 (T21) mosaicism, the origin of AML must be related to a cytogenetic abnormality in chromosome $21[26,27]$. TMD is caused by cooperation between T21 and acquired somatic $\mathrm{N}$-terminal truncating mutations in the key haematopoietic transcription factor GATA1. These mutations, which are not leukaemogenic in the absence of T21, are found in almost one-third of neonates with DS. Analysis of primary human fetal liver haematopoietic cells and of human embryonic stem cells demonstrates that T21 itself substantially alters human fetal haematopoietic development [28]. 
TABLE 2: Diagnostic tests in malignancies involving the skin, with differential diagnosis $(*$ in addition to the different causes of blueberry muffin baby listed in Table 1; WBC: white blood cell; Hb: Haemoglobin; PLTs: platelets).

\begin{tabular}{|c|c|c|}
\hline Neoplasia & Diagnostic tests & Differential diagnosis* \\
\hline Leukemia & $\begin{array}{l}\text { (i) Blood cell count (WBC > 50000; low Hb and PLTs) } \\
\text { (ii) Liver function tests } \\
\text { (iii) Coagulation studies } \\
\text { (iv) Blood film } \\
\text { (v) Bone marrow aspirate with morphology, } \\
\text { immunophenotype (FAB L1, L2, M4, M5, and M7), and } \\
\text { karyotypes [t( } 4 ; 11)(\mathrm{q} 21 ; \mathrm{q} 23) ; \mathrm{t}(11 ; 19)(\mathrm{q} 23 ; \mathrm{p} 13) \text {; } \\
\mathrm{t}(9 ; 11)(\mathrm{p} 21 ; \mathrm{q} 23) ; \mathrm{t}(1 ; 22)(\mathrm{p} 13 ; \mathrm{q} 13)] \text { of blasts } \\
\text { (vi) Skin biopsy }\end{array}$ & $\begin{array}{l}\text { (i) Listeriosis } \\
\text { (ii) Sepsis } \\
\text { (iii) Intrauterine Parvovirus infection } \\
\text { (iv) Congenital HIV } \\
\text { (v) Diamond Blackfan anemia } \\
\text { (vi) Extramedullary hematopoiesis } \\
\text { (vii) Intrauterine or birth-related hypoxia } \\
\text { (viii) Neonatal lupus erythematosus }\end{array}$ \\
\hline TMD & $\begin{array}{l}\text { (i) Blood cell count (WBC } 100000-50000 \text { or normal; normal } \\
\text { or decreased Hb; and decreased PLTs) } \\
\text { (ii) Liver function tests (increased bilirubin and/or } \\
\text { transaminases) } \\
\text { (iii) Coagulation studies (abnormal coagulation) } \\
\text { (iv) Renal function tests } \\
\text { (v) Abdominal ultrasound } \\
\text { (vi) Echocardiography } \\
\text { (vii) Chest X-ray } \\
\text { (viii) Blood film } \\
\text { (ix) Bone marrow aspirate with morphology, } \\
\text { immunophenotype (FAB M7), and karyotypes (GATA 1) of } \\
\text { blasts }\end{array}$ & $\begin{array}{l}\text { (i) Nonspecific changes associated with intrauterine } \\
\text { growth restriction and trisomies: neutropenia, } \\
\text { thrombocytopenia, erythroblastosis, and } \\
\text { polycythaemia } \\
\text { (ii) Subtle myelodysplastic features: abnormal myeloid } \\
\text { cell granulation, giant platelets }\end{array}$ \\
\hline $\mathrm{LCH}$ & $\begin{array}{l}\text { (i) Blood cell count (normal or decreased Hb, RBC, and/or } \\
\text { PLTs) } \\
\text { (ii) Liver function tests } \\
\text { (iii) Coagulation studies } \\
\text { (iv) Chest X-ray } \\
\text { (v) Abdominal ultrasound } \\
\text { (vi) Skin biopsy }\end{array}$ & $\begin{array}{l}\text { (i) Hemophagocytic lymphohistiocytosis } \\
\text { (ii) Familial erythrophagocytic lymphohistiocytosis } \\
\text { (iii) Infection-associated hemophagocytic syndrome } \\
\text { (iv) Hemangioendotheliomas } \\
\text { (v) Extramedullary hematopoiesis } \\
\text { (vi) Lymphatic malformations } \\
\text { (vii) Infantile myofibromatosis } \\
\text { (viii) Histiocytomas } \\
\text { (ix) Fibrosarcoma } \\
\text { (x) Peripheral Primitive Neuroectodermal Tumor }\end{array}$ \\
\hline NB & $\begin{array}{l}\text { (i) Blood cell count (possible anemia and cytopenias) } \\
\text { (ii) Lactate dehydrogenase levels } \\
\text { (iii) Ferritin } \\
\text { (iv) Liver and renal function tests } \\
\text { (v) Urine catecholamines (increased homovanillic and } \\
\text { vanillylmandelic acid) } \\
\text { (vi) Abdominal and cerebral ultrasound } \\
\text { (vii) Chest X-ray } \\
\text { (viii) If necessary, brain, neck, and chest MRI } \\
\text { (ix) Skin biopsy with karyotypes (MYCN amplification) } \\
\text { (x) Bone marrow aspirate }\end{array}$ & $\begin{array}{l}\text { (i) Benign cutaneous epithelioid Schwannoma } \\
\text { (ii) Ganglioneuroma } \\
\text { (iii) Ganglioneuroblastoma }\end{array}$ \\
\hline RT & $\begin{array}{l}\text { (i) Urinalysis and renal function tests } \\
\text { (ii) Abdominal ultrasound } \\
\text { (iii) Chest X-ray } \\
\text { (iv) Brain ultrasound } \\
\text { (v) If necessary, brain MRI } \\
\text { (vi) Skin biopsy with karyotypes (SWI/SNF at 22q11.2) }\end{array}$ & $\begin{array}{l}\text { (i) Wilms' tumor } \\
\text { (ii) Medulloblastoma } \\
\text { (iii) Sarcomas } \\
\text { (iv) Hemangioma }\end{array}$ \\
\hline RMS & $\begin{array}{l}\text { (i) Blood cell count (normal or decreased PLTs, anemia) } \\
\text { (ii) Liver function tests }\end{array}$ & $\begin{array}{l}\text { (i) Wilms' tumor } \\
\text { (ii) Sarcomas }\end{array}$ \\
\hline
\end{tabular}

3.1. Clinical Presentation. TMD has variable presentation in the fetus and the newborn from mild disease to disseminated leukaemic infiltration and fulminant hepatic fibrosis. Approximately $10-25 \%$ of newborns are asymptomatic and present with circulating blast cells, with or without leucocytosis. Babies with clinical symptoms most commonly present with hepatomegaly, splenomegaly, jaundice, and/or pleural/pericardial effusions. Less common presentations include liver fibrosis, ascites, and renal failure. 


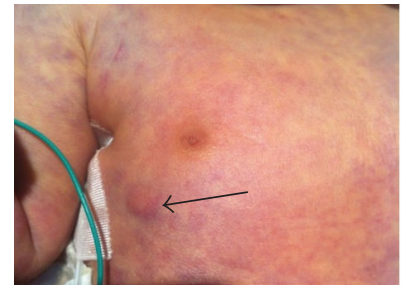

(a)

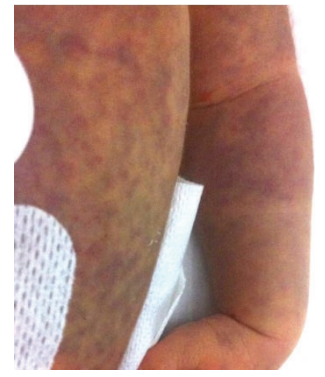

(b)

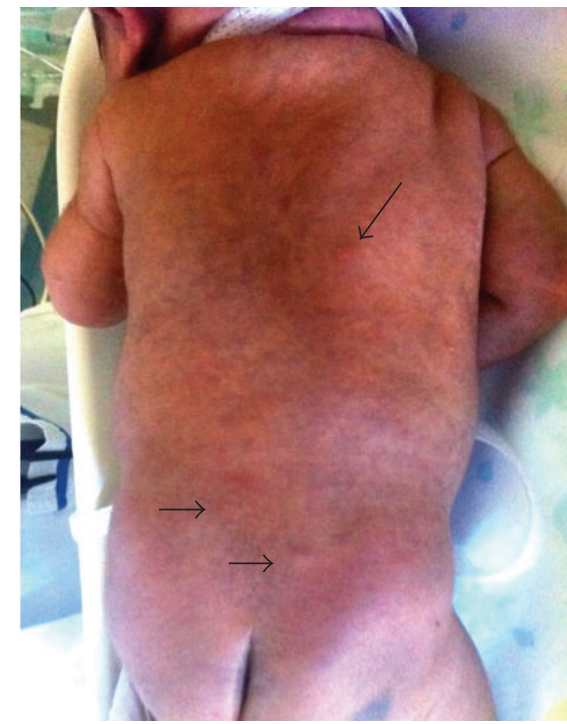

(c)

FIGURE 1: Skin involvement in the leukemia cutis, in a newborn on the first day of life. Randomly distributed subcutaneous nodules (arrows) on the chest (particularly in (a)) and on the trunk (c) with bluish infiltrates on the whole body surface (c) and particularly on the chest and the arm in (a) and (b). The blood cell rose until 167300/mcl, with prevalence of monocytes, low platelets count, and low hemoglobin levels. Infective pathologies have been excluded. The peripheral smear permitted the diagnosis of AML with positivity for CD45, CD33, CD14, CD13 heterogeneous, CD11b, and CD16 dull (AML-4). Genetic analysis revealed t(8;16)(p11;p13). After starting chemotherapy with aracytin, idarubicin, cytarabine, and etoposide, he died at 2 months of life.

The eruption, due to the cutaneous dissemination of the leukemic cells, is apparently more frequent in males and usually develops during the first days of life. Usually it is not associated with fever or respiratory distress, but infants present with high white blood cells count in the peripheral smear. Therefore, in newborns with diagnosed or suspected DS, presenting with cutaneous lesion, TMD needs to be considered as a possible differential diagnosis. The recognition of this rare clinical entity can be important to differentiate other dermatoses requiring totally different management, such as bacterial, viral, or fungal infections, histiocytosis, incontinentia pigmenti, and, of course, leukemia cutis; therefore, further specification of the clinical and histopathological findings is needed.

Because of the possible evolution in acute leukemia DS patients with TMD have to be strictly monitored to eventually start early therapy if needed.

3.2. Skin Involvement. This unusual form of vesiculopustular eruption is due to the cutaneous dissemination of the leukemic cells and usually develops during the first days of life. The primary lesions are papules, vesicles, or pustules that can rupture and originate erosion and serosanguinous crusts (Figure 2); the face is almost invariably involved, but other lesions often develop elsewhere and can be observed over any skin site, including scalp, palms, and soles. Cutaneous histopathology shows intraepidermal vesicles or pustules (Figure 3) and a dermal mixed inflammatory infiltrate including atypical mononuclear cells. Clearing without scarring is spontaneous over few weeks or months, depending on the course of the underlying haematological disorder, but antiblastic agents and topical corticosteroids have been reported to accelerate the remission of the cutaneous picture.

\section{Langerhans Cell Histiocytosis}

The histiocytoses are a diverse group of diseases characterized by the infiltration and accumulation of histiocytes primarily within the blood and tissues. Langerhans cell histiocytosis (LCH) is the main histiocytosis occurring in the neonatal period, followed in order by hemophagocytic lymphohistiocytosis (Figure 4) and juvenile xanthogranuloma [29-32]. Neonatal LCH is rare, with a reported incidence of 1 per 1 million newborns. Approximately $50 \%$ of cases involving multiple organs are at higher risk of disease-related mortality $[29,33]$. It is a rare disease marked by proliferation of Langerhans-type cells, which shares immunophenotypic and ultrastructural similarities with antigen-presenting Langerhans cells of mucosal sites and skin [34].

The condition was initially described by Lichtenstein in 1953 and referred to as histiocytosis $X$ to reflect the uncertain cause and often contrasting features of 3 clinical variants: Letterer-Siwe disease, Hand-Schüller-Christian disease, and eosinophilic granuloma [35]. Recently, the unifying term Langerhans cell histiocytosis has replaced histiocytosis $X$, including congenital self-healing reticulohistiocytosis [36], Langerhans cell granulomatosis, and nonlipid reticuloendotheliosis. It is now the preferred terminology of any disorder caused by proliferation of Langerhans cells.

Different oncogenic mutations have been involved in the LCH pathogenesis. 


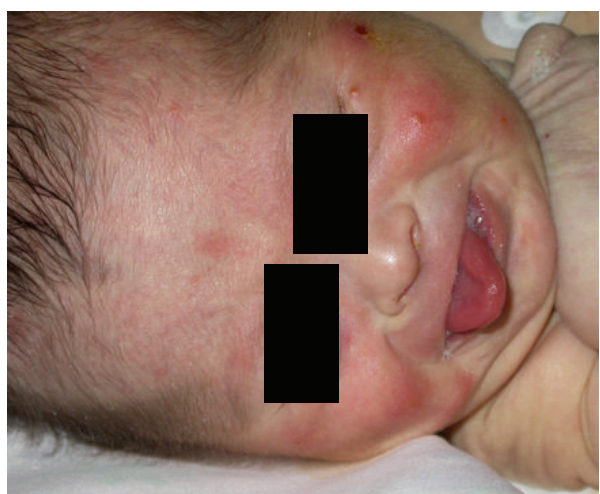

(a)

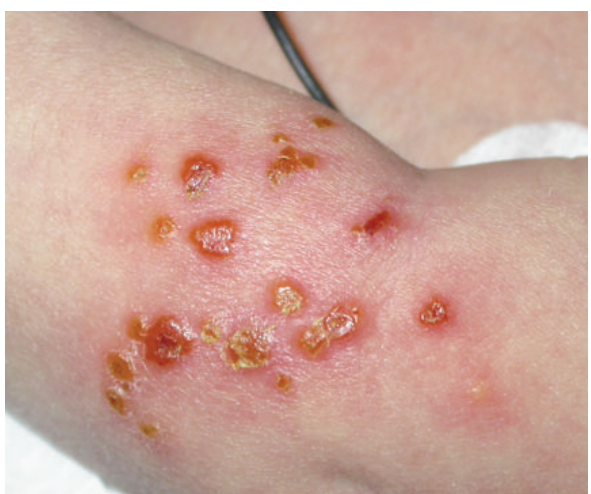

(b)

Figure 2: Lesions in a male neonate with Down syndrome, affected by TMD. Gradually, we observed evolution of the skin lesion, such as vesiculopustular eruption on the face (a) and vesiculopustular eruption on arm (b). A biopsy of the lesions showed mild acanthosis epidermis that was focally eroded. Within the superficial dermis and extending into the epidermis were large mononuclear cells with hyperchromatic nuclei and abundant eosinophilic cytoplasm consistent with immature myeloid cells. Immunohistochemical stains showed strong immunoreactivity of these cells with myeloperoxidase and a megakaryocytic cell marker LAT (linker for activation of T cells), confirming that the cells were of myeloid and megakaryoblastic origin (Figure 3). The histologic findings supported the clinical suspicion of a TMD.

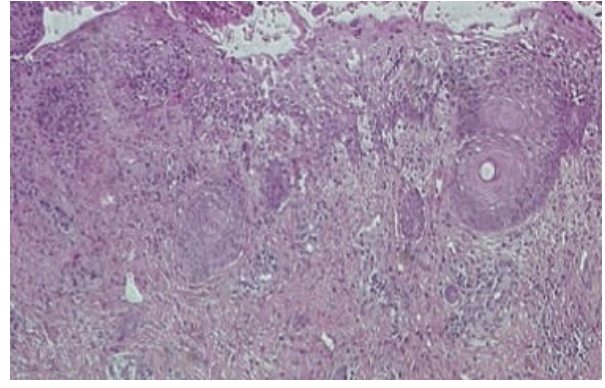

(a)

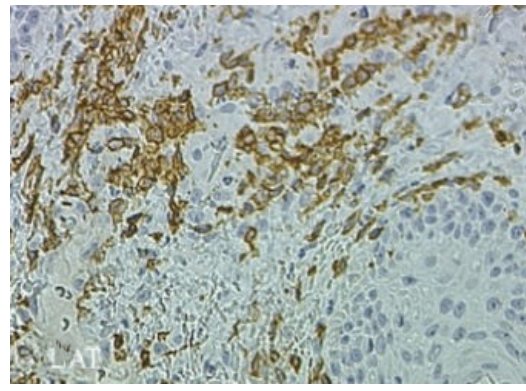

(b)

FIGURE 3: Image of cutaneous lesion biopsy, low-power magnification showing intraepidermal pustule and dermal perivascular infiltrates (hematoxylin-eosin staining) 10x (a). Immunoreaction for LAT (linker for activation of T cells): the cells in the dermis look like atypical blasts of myeloid and megakaryocytic lineage (b).

BRAFV600E has been detected in more than half of the cases of LCH in adult age. BRAFV600E mutation results in constitutive activation of the mitogen-activated protein kinase (MAPK) pathway; it has been observed that the MAPK pathway is also activated in cases of $\mathrm{LCH}$ without mutations of $B R A F$ [37]. Mutations in $M A P 2 K 1$, which encodes the dual-specificity kinase MEK1 protein in the MAPK pathway, have been identified in $27.5 \%$ of cases with $\mathrm{LCH}$, thus explaining MAPK pathway activation in the absence of the $B R A F$ mutation. $M A P 2 K 1$ and $B R A F$ mutations were found to be mutually exclusive, as would be expected since MEK1 is directly downstream BRAF within the MAPK pathway [38]. Additional cases of other mutations in the MAPK genes have also been reported, including ARAF and ERBB3 $[39,40]$.

4.1. Clinical Presentation. LCH is characterized by the infiltration and accumulation of histiocytes and other immune effector cells within various tissues. In addition to blue nodules, other typical cutaneous lesions are scaly, erythematous, seborrhoea-like eruptions of brown to red papules. Superficial ulcerations within these lesions are also described resulting in weeping lesions suggestive of eczema.

In addition, patients with multisystem disease have involvement of at least one other system, including the bone, lymph nodes, the central nervous system, the eye, the gastrointestinal tract, the bone marrow, or solid organs. Patients may present with pain, dyspnoea, and failure to thrive $[33,41]$.

4.2. Skin Involvement. Various skin findings are characteristic of $\mathrm{LCH}$. The most common lesions are red brown papules or nodules that may be pseudo vesicular and often crusty. They can be associated with secondary erosion or hemorrhage. In addition, erythematous, scaly dermatitis involving the scalp, posterior auricular regions, perineum, and/or axillae can be seen $[42,43]$. 


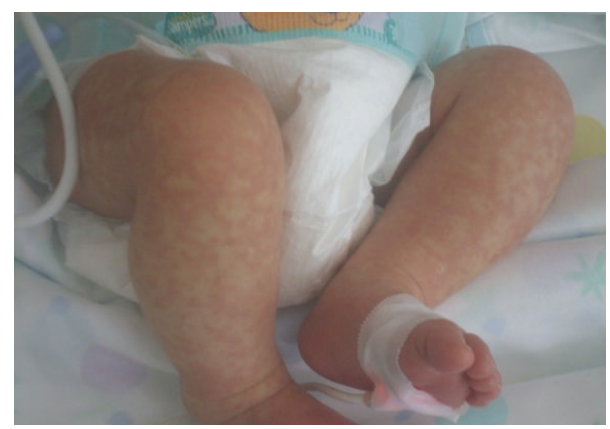

FIgURE 4: A reticulated, maculopapular rash in the lower limb in a term male affected by haemophagocytic lymphohistiocytosis. He presented with fever associated with generalized rash which disappeared in the first week of life and appeared again on 30th day. Blood test analysis showed values indicative of liver failure; blood cell count revealed low platelets values. The abdominal ultrasound scan showed thinly irregular liver parenchyma. Hypoplasia of granulocyte and erythroblastic and megakaryocytic lineages ( $<5 \%$ each) with haematopoietic cell phagocytosis by mature macrophages were present in the bone marrow aspirate. High-dose glucocorticoids, cyclosporine, and etoposide were started. Despite the therapy, there has been gradual deterioration of the clinical condition until coma, respiratory failure, intractable hypotension, and coagulopathy led to death despite intensive vital support.

A skin biopsy provides a rapid and accessible means to secure the diagnosis. A presumptive diagnosis of $\mathrm{LCH}$ may be made based upon light microscopic findings and a compatible clinical picture, but a definitive diagnosis requires that lesional cells exhibit positive staining with S-100 and CDla, and the identification of Birbeck granules upon electron microscopy is necessary [44].

\section{Neuroblastoma}

Neuroblastoma (NB) is the most common neonatal malignancy. The Automated Childhood Cancer Information System (ACCIS) revealed an incidence of $27 \%$ of cancers cases in Europe between 1978 and 1997, with the highest incidence in the first year of life [45]. One study reported that $16 \%$ of infant neuroblastomas were diagnosed during the first month of life and $42 \%$ during the first 3 months [46]. Stage 4 S represents approximately $7-10 \%$ of all cases of NB. Most neuroblastomas occur sporadically; familial NB per se is rare and concerns only approximately $1 \%$ of all cases [47]. Different genomic mutations have been identified in the last decades. The most important alteration is $M Y C N$ amplification, which is strongly correlated with advanced disease, drug resistance, and poor outcome [48]. The amplification of MYCN and the subsequent overexpression of the protein directly contribute to tumorigenesis. MYCN oncogene is predominantly expressed in the developing peripheral neural crest inducing proliferation and migration, with decreased levels associated with terminal differentiation [49]. Missense mutations of Paired Homeobox 2b (PHOX2B) on chromosome $4 \mathrm{p}$, frequently associated with other neural crest disorders or malignancies (Ondine's and Hirschsprung's disease), were the first germline mutations to be identified in NB predisposition [50-52]. More recently, whole exome and whole genome sequencing analyses have identified loss-offunction mutations/deletions in chromatin modifiers including ATRX, ARIDIA, and ARID1B. However, ATRX mutations were more common in patients over 5 years of age and no mutations/deletions were identified in the youngest age group $(<18$ months) [53].

In neonates and infants aged $<18$ months, NB has a good prognosis as most have favourable biological characteristics and may undergo spontaneous regression even if metastatic. Diagnosis can occasionally be performed during pregnancy by fetal ultrasound [54].

5.1. Clinical Presentation. Multiple nodules occur in more than one-third of patients and are characteristic of stage $4 \mathrm{~S}$ disease. Stage $4 \mathrm{~S} \mathrm{NB}$ is defined by the International Neuroblastoma Staging System (INSS) as metastatic disease with metastases confined to skin, liver, and/or bone marrow in infants younger than one. According to the Stage International Neuroblastoma Risk Group, based on clinical criteria and image-defined risk factors, the age for stage $4 \mathrm{~S}$ (also called stage MS) has been extended to 18 months $[55,56]$.

Stage 4S (or MS) can also present with rapid enlarging, diffusively involved liver ("Pepper Syndrome"), which may cause respiratory compromise, renal impairment, and bowel dysfunction together with coagulopathy. NB can also cause spinal cord compression in the neonate, with bladder and bowel dysfunction as well as motor impairment $[57,58]$.

5.2. Skin Involvement. The typical cutaneous eruption is represented by bluish cutaneous nodules with a characteristic blanch response to palpation that leaves surrounding rim of erythema. Ocular signs such as "raccoon eyes," periorbital ecchymosis, or heterochromia iridis may be present [59].

Histological examination of the cutaneous nodules reveals a uniform, small cell, malignant tumor with or without Homer-Wright pseudo rosette formation. Molecularly, $\mathrm{NB}$ stage $4 \mathrm{~S}$ is characterised by near triploidy and absence of genetic alterations. Structural genetic changes characteristic of stage $4 \mathrm{NB}$ (e.g., segmental chromosomal alterations, $M Y C N$ amplification, and $A L K$ mutations) are not present in children with NB stage 4 S, but if they are present, the tumor behaves as if it was a stage $4 \mathrm{NB}$.

\section{Rhabdoid Tumor}

Rhabdoid tumor (RT) was distinguished from Wilms' tumor in the 1970s. This highly malignant neoplasm is characterized by early metastases and a high mortality rate. The tumor occurs in the perinatal period during the first year of life and occasionally in older children. According to the origin tissue the RT family is divided into 3 categories, with an approximately equal distribution: (1) primary central nervous system lesions, defined as atypical teratoid/rhabdoid tumor, associated with a low incidence of metastases outside the central nervous system, (2) primary renal lesions, and (3) primary soft tissue lesions. The latter typically relates to 


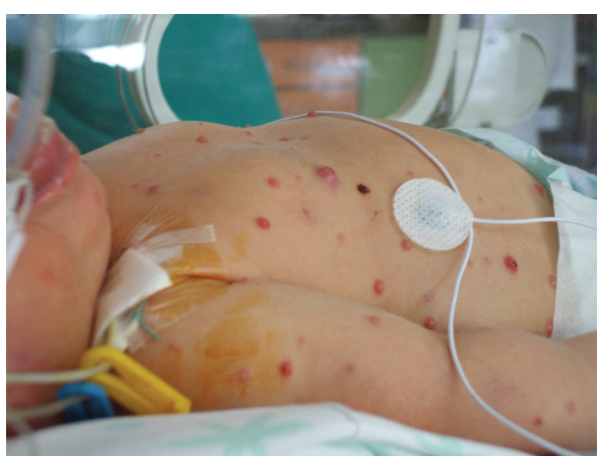

(a)

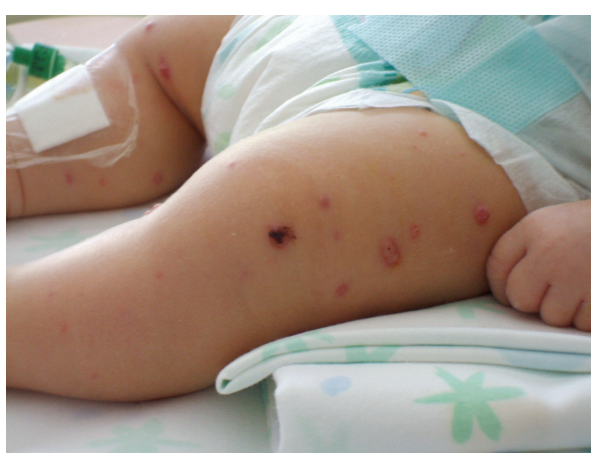

(b)

Figure 5: Nodular lesions diffused on the body in a term baby with alveolar rhabdomyosarcoma. Particular image of the chest and right arm (a) and the legs (b). An incisional biopsy of the cutis showed aggregates of atypical small spindle cells interrupted by fibrovascular septae and collagen bands resembling the lung alveoli. Bone marrow biopsy and total body CT scan demonstrated the presence of pulmonary, pleural, and pericardial metastasis. Chemotherapy was started, without a clinical improvement. The baby died at 26 days of life because of renal insufficiency and heart failure.

widespread metastatic disease [60-64]. The incidence of metastatic RT/atypical RT is not defined; however, European data indicate 0.1 to 0.5 per million children per year. Rhabdoid tumors not involving the kidney are very rare [65]. When RT occurs in utero, it is more likely to present at birth with multiple metastases and a rapidly progressive, downhill clinical course ending in early death. Metastatic disease is present in more than half of the neonates at the time of diagnosis.

The vast majority of RTs demonstrate abnormalities in chromosome 22 . These abnormalities are characterized by the loss of function of a member of the SWI/SNF chromatinremodeling complex located at 22q11.2, known with different names (hSNF5, INI1, BAF47, or SMARCB1) [66]. In RT, genetic mutations are characterized by somatically acquired biallelic inactivating truncating mutations within the tumor cells, associated or not with a predisposing germline mutation $[67,68]$.

6.1. Clinical Presentation. RT may present in the skin, particularly in the head and neck area, as a solitary primary tumor or as metastatic skin nodules. RTs have to be suspected in case of haematuria with or without hypercalcemia [69]. Neonates can also manifest an increase in cranial circumference due to hydrocephalus, seizures, and irritability because of CNS involvement. Moreover, vomiting, anaemia, fever, and respiratory distress can be present [70].

6.2. Skin Involvement. Few case reports describe the cutaneous involvement due to RT [70-72]. Typically primary central nervous system lesions can manifest themselves as one or several lightly erythematous papulonodular lesions. They seem to be verrucous, as observed with verrucous hamartomas.

The histologic diagnosis of RT is based on the identification of the characteristic RT cell, which consists of a round vesicular nucleus, a prominent nucleolus, and round to oval eosinophilic inclusion containing intermediate filaments as seen by electron microscopy $[64,73]$. Moreover, the presence of a mutation of the hsNF5/INI1 gene located in chromosome $22 \mathrm{q} 11$ is helpful in establishing the diagnosis.

\section{Rhabdomyosarcoma}

Rhabdomyosarcoma (RMS), the most common soft tissue sarcoma, represents $4-8 \%$ of all malignant solid tumors in childhood, with few cases described in infants younger than one month of life [74-76]. RMS may be congenital. RMS is traditionally subdivided into embryonal, alveolar, and pleomorphic. The overall prognosis of perinatal RMS is poor, with expected survival around 40\% [77].

7.1. Clinical Presentation. Most cases of RMS occur in the head and neck region (29.3\%) and in the genitourinary tract (26.3\%) [78]. Multiple skin nodules can be observed. In addition, neonates can be manifested with haemangioma-like vascular lesions and an abdominal mass; hepatosplenomegaly and thrombocytopenia can be associated. Neonatal Alveolar RMS (Figure 5) frequently manifests itself with multiple skin lesions associated with brain metastasis.

7.2. Skin Involvement. RMS is clinically manifested as multiple papulonodular lesions and subcutaneous nodules or as a single papule or nodule, which grows slowly. The lesions may present as soft cherry-red color nodules or as firm violaceous subcutaneous nodules [79].

Most cases of RMS skin metastasis are of the alveolar subtype, with small- to medium-sized darkly stained cells with rounded nuclei and scant cytoplasm arranged in alveolar pattern. It is often very difficult to differentiate the skin metastases of RMS from other skin neoplasms that are composed of spindle or round cells, such as lymphoma, NB, and Ewing's sarcoma [80]. The use of immunohistochemistry may provide additional information to aid in differential diagnosis. Cytogenetic analysis plays an important role in confirming the diagnosis, but only for alveolar RMS because 
there are no specific cytogenetic or molecular markers for embryonal RMS. Alveolar RMS is associated with specific translocation, $\mathrm{t}(2 ; 13)(\mathrm{q} 37 ; \mathrm{q} 14)$ or its variant $\mathrm{t}(1 ; 13)(\mathrm{p} 36 ; \mathrm{q} 14)$ [81].

\section{Other Tumors}

Few cases of other neoplasms with cutaneous involvement as first presentation in the first days of life are described. The rare Peripheral Primitive Neuroectodermal Tumor is characterized by the presence of small blue cells in the CNS and in peripheral tissues [80]. Neonatal choriocarcinoma, an aggressive malignant tumor of trophoblastic cells, with cutaneous metastasis has been described in four neonates [82]. The infantile myofibromatosis, the most common fibrous tumor of infancy, is characterized by the presence of myofibroblastic cells that involve the skin, soft tissue, bones, and internal organs [83].

\section{Conclusion}

The blueberry muffin rash as well as nodules, bruising, and crusts may all indicate serious underlying diseases and sometimes may represent the first clinical manifestation of rare neoplasms in the newborn infant. Clinical and laboratory findings can be limited and clinic-pathological correlation is critical. A definitive diagnosis can be obtained only by means of a skin biopsy. Treatment options pose challenges because of the particular vulnerability of the affected neonates. Neonatal cancer raises diagnostic, therapeutic, and ethical issues; management requires a multidisciplinary approach. The prognosis depends on the type of cancer identified, the optimal timing of the therapy, and the subsequent follow-up.

\section{Conflict of Interests}

The authors declare that there is no conflict of interests regarding the publication of this paper.

\section{References}

[1] S. E. Parkes, K. R. Muir, L. Southern, A. H. Cameron, P. J. Darbyshire, and M. C. G. Stevens, "Neonatal tumours: a thirtyyear population-based study," Medical and Pediatric Oncology, vol. 22, no. 5, pp. 309-317, 1994.

[2] J. M. Birch and V. Blair, "The epidemiology of infant cancers," British Journal of Cancer, vol. 66, pp. S52-S54, 1992.

[3] S. W. Moore, D. Satgé, A. J. Sasco, A. Zimmermann, and J. Plaschkes, "The epidemiology of neonatal tumours: report of an international working group," Pediatric Surgery International, vol. 19, no. 7, pp. 509-519, 2003.

[4] H. Isaacs Jr., "Cutaneous metastases in neonates: a review," Pediatric Dermatology, vol. 28, no. 2, pp. 85-93, 2011.

[5] H. R. Isaacs Jr., "Tumors and tumorlike conditions of the skin," in Tumors of the Fetus and Infant: An Atlas, pp. 113-135, Springer, New York, NY, USA, 2002.

[6] H. R. Isaacs Jr., "Pathology of skin diseases," in Potter's Pathology of the Fetus, Infant and Child, E. Gilbert-Barness, Ed., vol. 2, pp.
1743-1795, Mosby Elsevier, Philadelphia, Pa, USA, 2nd edition, 2007.

[7] S. Weitzman and R. Grant, "Neonatal oncology: diagnostic and therapeutic dilemmas," Seminars in Perinatology, vol. 21, no. 1, pp. 102-111, 1997.

[8] T. S. Wright, "Cutaneous manifestations of malignancy," Current Opinion in Pediatrics, vol. 23, no. 4, pp. 407-411, 2011.

[9] M. H. Van der Linden, S. Creemers, and R. Pieters, "Diagnosis and management of neonatal leukaemia," Seminars in Fetal and Neonatal Medicine, vol. 17, no. 4, pp. 192-195, 2012.

[10] H. Isaacs Jr., "Fetal and neonatal leukemia," Journal of Pediatric Hematology/Oncology, vol. 25, no. 5, pp. 348-361, 2003.

[11] M. P. Bas Suárez, J. López Brito, C. Santana Reyes, M. Gresa Muñoz, R. Diaz Pulido, and J. C. Lodos Rojas, "Congenital acute lymphoblastic leukemia: a two-case report and a review of the literature," European Journal of Pediatrics, vol. 170, no. 4, pp. 531$534,2011$.

[12] D. Bresters, A. C. Reus, A. J. Veerman, E. R. van Wering, A. van der Does-van den Berg, and G. J. Kaspers, "Congenital leukaemia: the Dutch experience and review of the literature," British Journal of Haematology, vol. 117, no. 3, pp. 513-524, 2002.

[13] H. Chang, J. Brandwein, Q.-L. Yi, K. Chun, B. Patterson, and B. Brien, "Extramedullary infiltrates of AML are associated with CD56 expression, 11q23 abnormalities and inferior clinical outcome," Leukemia Research, vol. 28, no. 10, pp. 1007-1011, 2004.

[14] M. Y. Hurley, G. K. Ghahramani, S. Frisch et al., "Cutaneous myeloid sarcoma: natural history and biology of an uncommon manifestation of acute myeloid leukemia," Acta DermatoVenereologica, vol. 93, no. 3, pp. 319-324, 2013.

[15] E. A. Coenen, C. M. Zwaan, D. Reinhardt et al., "Pediatric acute myeloid leukemia with $\mathrm{t}(8 ; 16)$ (p11;p13), a distinct clinical and biological entity: a collaborative study by the InternationalBerlin-Frankfurt-Munster AML-study group," Blood, vol. 122, no. 15, pp. 2704-2713, 2013.

[16] X.-O. Shu, J. A. Ross, T. W. Pendergrass, G. H. Reaman, B. Lampkin, and L. L. Robison, "Parental alcohol consumption, cigarette smoking, and risk of infant leukemia: a Childrens Cancer Group study," Journal of the National Cancer Institute, vol. 88, no. 1, pp. 24-31, 1996.

[17] L. L. Robison, J. D. Buckley, A. E. Daigle et al., "Maternal drug use and risk of childhood nonlymphoblastic leukemia among offspring. An epidemiologic investigation implicating marijuana (a report from the childrens cancer study group)," Cancer, vol. 63, no. 10, pp. 1904-1911, 1989.

[18] J. A. Ross, "Dietary flavonoids and the MLL gene: a pathway to infant leukemia?" Proceedings of the National Academy of Sciences of the United States of America, vol. 97, no. 9, pp. 44114413, 2000.

[19] H. van den Berg, A. H. N. Hopman, K. C. Kraakman, and D. De Jong, "Spontaneous remission in congenital leukemia is not related to (MOSAIC) trisomy 21: case presentation and literature review," Pediatric Hematology and Oncology, vol. 21, no. 2, pp. 135-144, 2004.

[20] P. Porcu, S. Farag, G. Marcucci, S. R. Cataland, M. S. Kennedy, and M. Bissell, "Leukocytoreduction for acute leukemia," Therapeutic Apheresis, vol. 6, no. 1, pp. 15-23, 2002.

[21] M. O. Arcasoy and P. G. Gallagher, "Hematologic disorders and nonimmune hydrops fetalis," Seminars in Perinatology, vol. 19, no. 6, pp. 502-515, 1995. 
[22] T. A. Longacre and B. R. Smoller, "Leukemia cutis. Analysis of 50 biopsy-proven cases with an emphasis on occurrence in myelodysplastic syndromes," American Journal of Clinical Pathology, vol. 100, no. 3, pp. 276-284, 1993.

[23] E. Sotiriou, A. Manousari, Z. Apalla, I. Papagarifallou, and D. Ioannides, "Aleukaemic congenital leukaemia cutis: a critical primary sign of systemic disease," Acta Dermato-Venereologica, vol. 91, no. 2, pp. 203-204, 2011.

[24] I. H. Zhang, L. T. Zane, B. S. Braun, J. Maize Jr., S. Zoger, and M. L. Loh, "Congenital leukemia cutis with subsequent development of leukemia," Journal of the American Academy of Dermatology, vol. 54, no. 2, pp. S22-S27, 2006.

[25] G. J. Schunk and W. L. Lehman, "Mongolism and congenital leukemia," The Journal of the American Medical Association, vol. 155, no. 3, pp. 250-251, 1954.

[26] G. V. Massey, A. Zipursky, M. N. Chang et al., "A prospective study of the natural history of transient leukemia (TL) in neonates with Down syndrome (DS): Children's Oncology Group (COG) study POG-9481," Blood, vol. 107, no. 12, pp. 4606-4613, 2006.

[27] G. V. Massey, "Transient leukemia in newborns with Down syndrome," Pediatric Blood and Cancer, vol. 44, no. 1, pp. 2932, 2005.

[28] I. Roberts and S. Izraeli, "Haematopoietic development and leukaemia in Down syndrome," British Journal of Haematology, vol. 167, no. 5, pp. 587-599, 2014.

[29] H. Isaacs Jr., "Fetal and neonatal histiocytoses," Pediatric Blood and Cancer, vol. 47, no. 2, pp. 123-129, 2006.

[30] D. S. Morrel, M. A. Pepping, J. P. Scott, N. B. Esterly, and B. A. Drolet, "Cutaneous manifestation of hemophagocitic lymphohistiocytosis," Archives of Dermatology, vol. 138, pp. 1208-1212, 2002.

[31] O. Danhaive, M. Caniglia, R. Devito, F. Piersigilli, C. Corchia, and C. Auriti, "Neonatal liver failure and haemophagocytic lymphohistiocytosis caused by a new perforin mutation," Acta Paediatrica, vol. 99, no. 5, pp. 778-780, 2010.

[32] D. R. Freyer, R. Kennedy, B. C. Bostrom, G. Kohut, and L. P. Dehner, "Juvenile xanthogranuloma: forms of systemic disease and their clinical implications," Journal of Pediatrics, vol. 129, no. 2, pp. 227-237, 1996.

[33] M. Minkov, H. Prosch, M. Steiner et al., "Langerhans cell histiocytosis in neonates," Pediatric Blood and Cancer, vol. 45, no. 6, pp. 802-807, 2005.

[34] R. Jaffe, L. M. Weiss, and F. Facchetti, "Tumours derived from Langerhans cells," in WHO Classification of Tumours of Haematopoietic and Lymphoid Tissues, S. H. Swerdlow, E. Campo, N. L. Harris et al., Eds., vol. 2 of World Health Organization Classification of Tumours, pp. 358-360, IARC Press, Lyon, France, 4th edition, 2008.

[35] A. C. Chu, R. H. Champion, J. L. Burton, and D. A. Burns, "Histiocytoses," in Rook's Textbook of Dermatology, S. M. Breathnach, Ed., pp. 2311-2336, Blackwell Science, London, UK, 1998.

[36] M. Inuzuka, K. Tomita, Y. Tokura, and M. Takigawa, "Congenital self-healing reticulohistiocytosis presenting with hemorrhagic bullae," Journal of the American Academy of Dermatology, vol. 48, no. 5, supplement, pp. S75-S77, 2003.

[37] G. Badalian-Very, J.-A. Vergilio, B. A. Degar et al., "Recurrent BRAF mutations in Langerhans cell histiocytosis," Blood, vol. 116, no. 11, pp. 1919-1923, 2010.
[38] N. A. Brown, L. V. Furtado, B. L. Betz et al., "High prevalence of somatic MAP2K1 mutations in BRAF V600E-negative Langerhans cell histiocytosis," Blood, vol. 124, no. 10, pp. 1655-1658, 2014.

[39] R. Chakraborty, O. A. Hampton, X. Shen et al., "Mutually exclusive recurrent somatic mutations in MAP2K1 and BRAF support a central role for ERK activation in LCH pathogenesis," Blood, vol. 124, no. 19, pp. 3007-3015, 2014.

[40] D. S. Nelson, W. Quispel, G. Badalian-Very et al., "Somatic activating ARAF mutations in Langerhans cell histiocytosis," Blood, vol. 123, no. 20, pp. 3152-3155, 2014.

[41] S. L. Stein, A. S. Paller, P. R. Haut, and A. J. Mancini, "Langerhans cell histiocytosis presenting in the neonatal period: a retrospective case series," Archives of Pediatrics and Adolescent Medicine, vol. 155, no. 7, pp. 778-783, 2001.

[42] A. Paller, A. J. Mancini, A. Hurwitz, S. Paller, and A. Mancini, "Histiocytoses and malignant skin diseases," in Hurwitz Clinical Pediatric Dermatology: A Textbook of Skin Disorders of Childhood and Adolescence, pp. 245-263, WB Saunders, Philadelphia, $\mathrm{Pa}, \mathrm{USA}, 3$ rd edition, 2011.

[43] M. J. Ehrhardt, S. R. Humphrey, M. E. Kelly, Y. E. Chiu, and S. S. Galbraith, "The natural history of skin-limited Langerhans cell histiocytosis: a single-institution experience," Journal of Pediatric Hematology/Oncology, vol. 36, no. 8, pp. 613-616, 2014.

[44] E. K. Satter and W. A. High, "Langerhans cell histiocytosis: a review of the current recommendations of the Histiocyte Society," Pediatric Dermatology, vol. 25, no. 3, pp. 291-295, 2008.

[45] C. Spix, G. Pastore, R. Sankila, C. A. Stiller, and E. SteliarovaFoucher, "Neuroblastoma incidence and survival in European children (1978-1997): report from the Automated Childhood Cancer Information System project," European Journal of Cancer, vol. 42, no. 13, pp. 2081-2091, 2006.

[46] S. Dhir and K. Wheeler, "Neonatal neuroblastoma," Early Human Development, vol. 86, no. 10, pp. 601-605, 2010.

[47] G. Schleiermacher, H. Rubie, O. Hartmann et al., "Treatment of stage 4 S neuroblastoma-report of 10 years' experience of the French Society of Paediatric Oncology (SFOP)," British Journal of Cancer, vol. 89, no. 3, pp. 470-476, 2003.

[48] G. M. Brodeur, "Neuroblastoma: biological insights into a clinical enigma," Nature Reviews Cancer, vol. 3, no. 3, pp. 203216, 2003.

[49] W. A. Weiss, K. Aldape, G. Mohapatra, B. G. Feuerstein, and J. M. Bishop, "Targeted expression of MYCN causes neuroblastoma in transgenic mice," The EMBO Journal, vol. 16, no. 11, pp. 2985-2995, 1997.

[50] N. Clausen, P. Andersson, and N. Tommerup, "Familial occurrence of neuroblastoma, von Recklinghausen's neurofibromatosis, Hirschsprung's agangliosis and jaw-winking syndrome," Acta Paediatrica Scandinavica, vol. 78, no. 5, pp. 736-741, 1989.

[51] T. Rohrer, D. Trachsel, G. Engelcke, and J. Hammer, "Congenital central hypoventilation syndrome associated with Hirschsprung's disease and neuroblastoma: case of multiple neurocristopathies," Pediatric Pulmonology, vol. 33, no. 1, pp. 7176, 2002.

[52] D. Trochet, L. M. O’Brien, D. Gozal et al., "PHOX2B genotype allows for prediction of tumor risk in congenital central hypoventilation syndrome," The American Journal of Human Genetics, vol. 76, no. 3, pp. 421-426, 2005.

[53] N.-K. V. Cheung, J. Zhang, C. Lu et al., "Association of age at diagnosis and genetic mutations in patients with neuroblastoma," The Journal of the American Medical Association, vol. 307, no. 10, pp. 1062-1071, 2012. 
[54] S. Acharya, S. Jayabose, S. J. Kogan et al., "Prenatally diagnosed neuroblastoma," Cancer, vol. 80, no. 2, pp. 304-310, 1997.

[55] G. M. Brodeur, J. Pritchard, F. Berthold et al., "Revisions of the international criteria for neuroblastoma diagnosis, staging, and response to treatment," Journal of Clinical Oncology, vol. 11, no. 8, pp. 1466-1477, 1993.

[56] T. Monclair, G. M. Brodeur, P. F. Ambros et al., "The International Neuroblastoma Risk Group (INRG) staging system: an INRG Task Force report," Journal of Clinical Oncology, vol. 27, no. 2, pp. 298-303, 2009.

[57] M. M. van Noesel, "Neuroblastoma stage 4S: a multifocal stemcell disease of the developing neural crest," The Lancet Oncology, vol. 13, no. 3, pp. 229-230, 2012.

[58] J. P. H. Fisher and D. A. Tweddle, "Neonatal neuroblastoma," Seminars in Fetal \& Neonatal Medicine, vol. 17, no. 4, pp. 207215, 2012.

[59] V. Mehta, C. Balachandran, and V. Lonikar, "Blueberry muffin baby: a pictoral differential diagnosis," Dermatology Online Journal, vol. 14, article 8, 2008.

[60] F. V. White, L. P. Dehner, D. A. Belchis et al., "Congenital disseminated malignant rhabdoid tumor: a distinct clinicopathologic entity demonstrating abnormalities of chromosome 22q11," The American Journal of Surgical Pathology, vol. 23, no. 3, pp. 249-256, 1999.

[61] M. Sajedi, J. E. A. Wolff, R. M. Egeler et al., "Congenital extrarenal non-central nervous system malignant rhabdoid tumor," Journal of Pediatric Hematology/Oncology, vol. 24, no. 4, pp. 316-320, 2002.

[62] L. B. Rorke, R. J. Packer, and J. A. Biegel, "Central nervous system atypical teratoid/rhabdoid tumors of infancy and childhood: definition of an entity," Journal of Neurosurgery, vol. 85, no. 1, pp. 56-65, 1996.

[63] C. Sotelo-Avila, F. Gonzalez-Crussi, D. deMello et al., "Renal and extrarenal rhabdoid tumors in children: a clinicopathologic study of 14 patients," Seminars in Diagnostic Pathology, vol. 3, no. 2, pp. 151-163, 1986.

[64] A. R. M. Cobb, N. J. Sebire, J. Anderson, and D. Dunaway, "Congenital malignant rhabdoid tumor of the scalp," Journal of Cranio-Maxillofacial Surgery, vol. 40, no. 8, pp. e258-e260, 2012.

[65] H. Reinhard, J. Reinert, R. Beier et al., "Rhabdoid tumors in children: prognostic factors in 70 patients diagnosed in Germany," Oncology Reports, vol. 19, no. 3, pp. 819-823, 2008.

[66] C. W. M. Roberts and J. A. Biegel, "The role of SMARCB1/INI1 in development of rhabdoid tumor," Cancer Biology and Therapy, vol. 8, no. 5, pp. 412-416, 2009.

[67] J. A. Biegel, L. Tan, F. Zhang, L. Wainwright, P. Russo, and L. B. Rorke, "Alterations of the hSNF5/INI1 gene in central nervous system atypical teratoid/rhabdoid tumors and renal and extrarenal rhabdoid tumors," Clinical Cancer Research, vol. 8, no. 11, pp. 3461-3467, 2002.

[68] J. A. Biegel, B. Fogelgren, L. M. Wainwright, J.-Y. Zhou, H. Bevan, and L. B. Rorke, "Germline INI1 mutation in a patient with a central nervous system atypical teratoid tumor and renal rhabdoid tumor," Genes, Chromosomes and Cancer, vol. 28, no. 1, pp. 31-37, 2000.

[69] A. M. Amar, G. Tomlinson, D. M. Green, N. E. Breslow, and P. A. de Alarcon, "Clinical presentation of rhabdoid tumors of the kidney," Journal of Pediatric Hematology/Oncology, vol. 23, no. 2, pp. 105-108, 2001.

[70] H. Isaacs Jr., "Fetal and neonatal rhabdoid tumor," Journal of Pediatric Surgery, vol. 45, no. 3, pp. 619-626, 2010.
[71] C. Hsueh and T.-T. Kuo, "Congenital malignant rhabdoid tumor presenting as a cutaneous nodule: report of 2 cases with review of the literature," Archives of Pathology and Laboratory Medicine, vol. 122, no. 12, pp. 1099-1102, 1998.

[72] A. Dominey, A. S. Paller, and F. Gonzalez-Crussi, "Congenital rhabdoid sarcoma with cutaneous metastases," Journal of the American Academy of Dermatology, vol. 22, no. 5, pp. 969-974, 1990.

[73] D. A. Weeks, J. B. Beckwith, G. W. Mierau, and D. W. Luckey, "Rhabdoid tumor of kidney: a report of 111 cases from the National Wilms' Tumor Study Pathology Center," The American Journal of Surgical Pathology, vol. 13, no. 6, pp. 439-458, 1989.

[74] S. V. Godambe and J. Rawal, "Blueberry muffin rash as a presentation of alveolar cell rhabdomyosarcoma in a neonate," Acta Paediatrica, vol. 89, no. 1, pp. 115-117, 2000.

[75] F. Piersigilli, O. Danhaive, and C. Auriti, "Blueberry muffin baby due to alveolar rhabdomyosarcoma with cutaneous metastasis," Archives of Disease in Childhood: Fetal and Neonatal Edition, vol. 95, article F461, 2010.

[76] N. Kitagawa, J. Arata, Y. Ohtsuki, K. Hayashi, Y. Oomori, and T. Tomoda, "Congenital alveolar rhabdomyosarcoma presenting as a blueberry muffin baby," Journal of Dermatology, vol. 16, no. 5, pp. 409-411, 1989.

[77] I. Sultan, M. Casanova, U. Al-Jumaily, C. Meazza, C. RodriguezGalindo, and A. Ferrari, "Soft tissue sarcomas in the first year of life," European Journal of Cancer, vol. 46, no. 13, pp. 2449-2456, 2010.

[78] C.-Y. Yang, I.-H. Shih, C.-M. Wang, and H.-L. Chan, "Embryonalrhabdomyosarcoma with skin invasion mimicking a perianal abcess," Dermatologica Sinica, vol. 18, pp. 219-222, 2000.

[79] R. Grundy, J. Anderson, M. Gaze et al., "Congenital alveolar rhabdomyosarcoma: clinical and molecular distinction from alveolar rhabdomyosarcoma in older children," Cancer, vol. 91, no. 3, pp. 606-612, 2001.

[80] C. Paley, E. Valderrama, M. Garcia, and G. Karayalcin, "Congenital peripheral neuroectodermal tumor presenting as disseminated cutaneous disease," Journal of Pediatric Hematology/Oncology, vol. 18, p. 447, 1996.

[81] C. De Giovanni, L. Landuzzi, G. Nicoletti, P.-L. Lollini, and P. Nanni, "Molecular and cellular biology of rhabdomyosarcoma," Future Oncology, vol. 5, no. 9, pp. 1449-1475, 2009.

[82] E. J. Johnson, P. M. Crofton, J. O’Neill et al., "Infantile choriocarcinoma treated with chemotherapy alone," Medical and Pediatric Oncology, vol. 41, no. 6, pp. 550-557, 2003.

[83] C. Auriti, M. W. Kieran, G. Deb, R. Devito, L. Pasquini, and O. Danhaive, "Remission of infantile generalized myofibromatosis after interferon alpha therapy," Journal of Pediatric Hematology/Oncology, vol. 30, no. 2, pp. 179-181, 2008. 


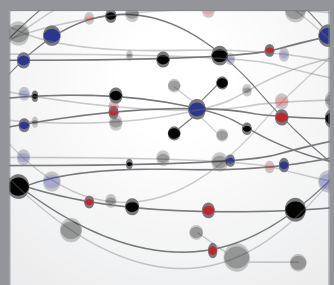

The Scientific World Journal
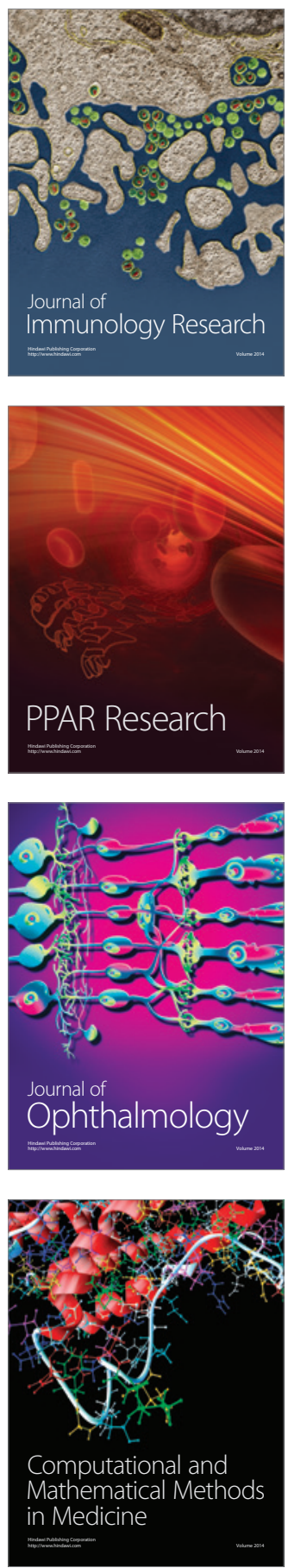

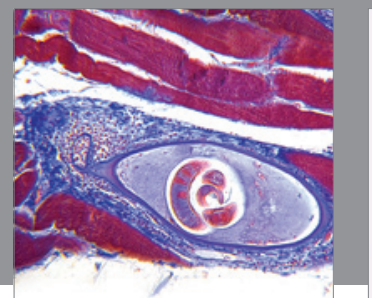

Gastroenterology

Research and Practice
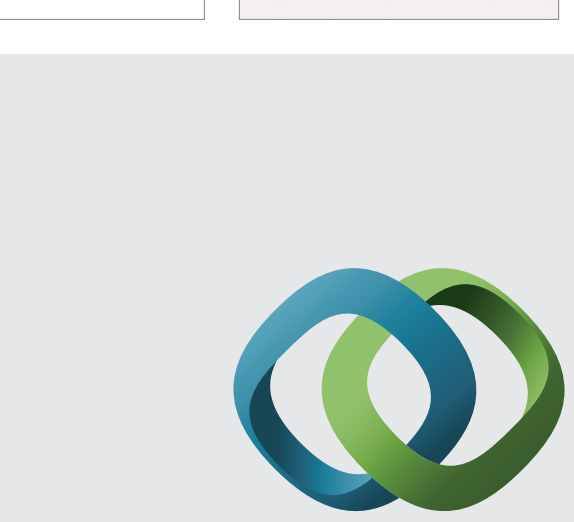

\section{Hindawi}

Submit your manuscripts at

http://www.hindawi.com
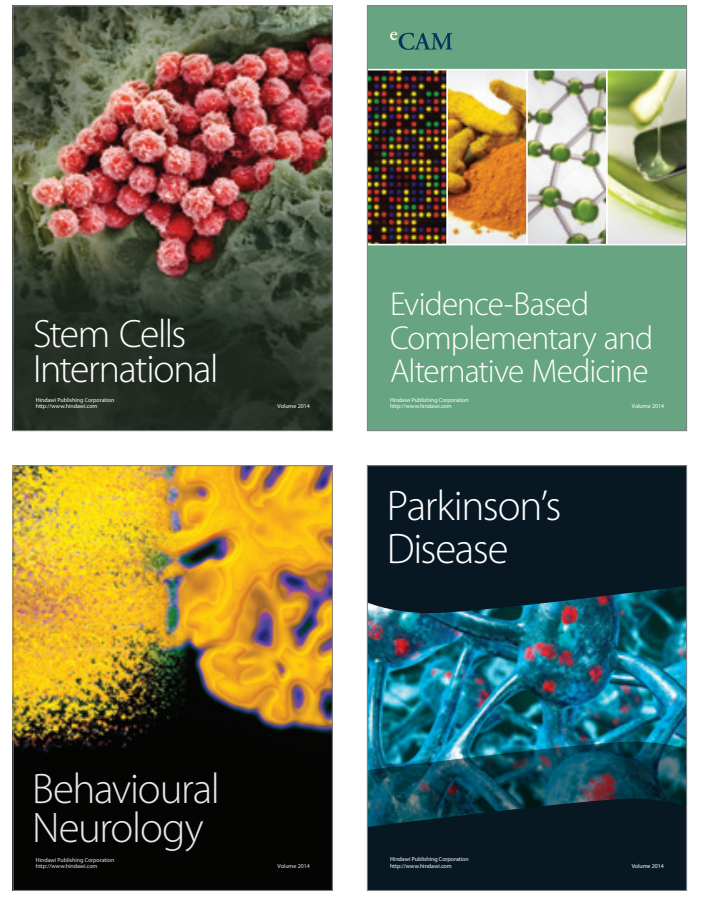
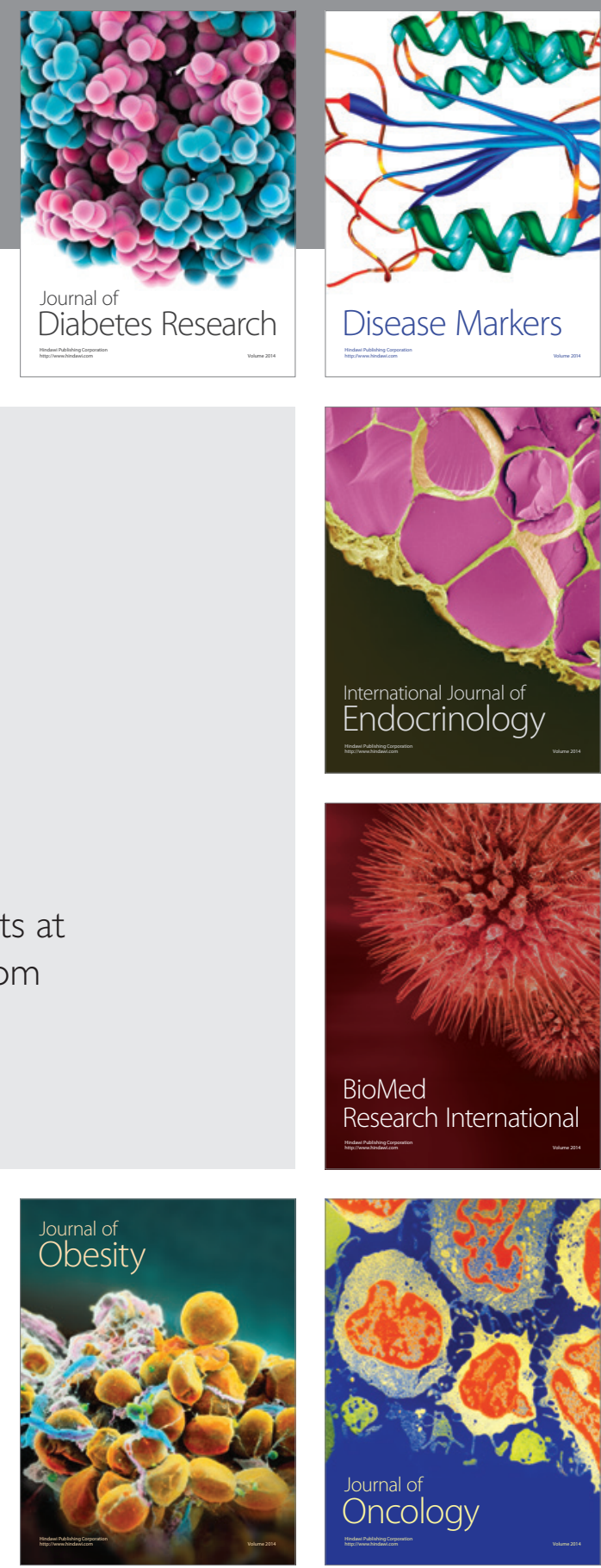

Disease Markers
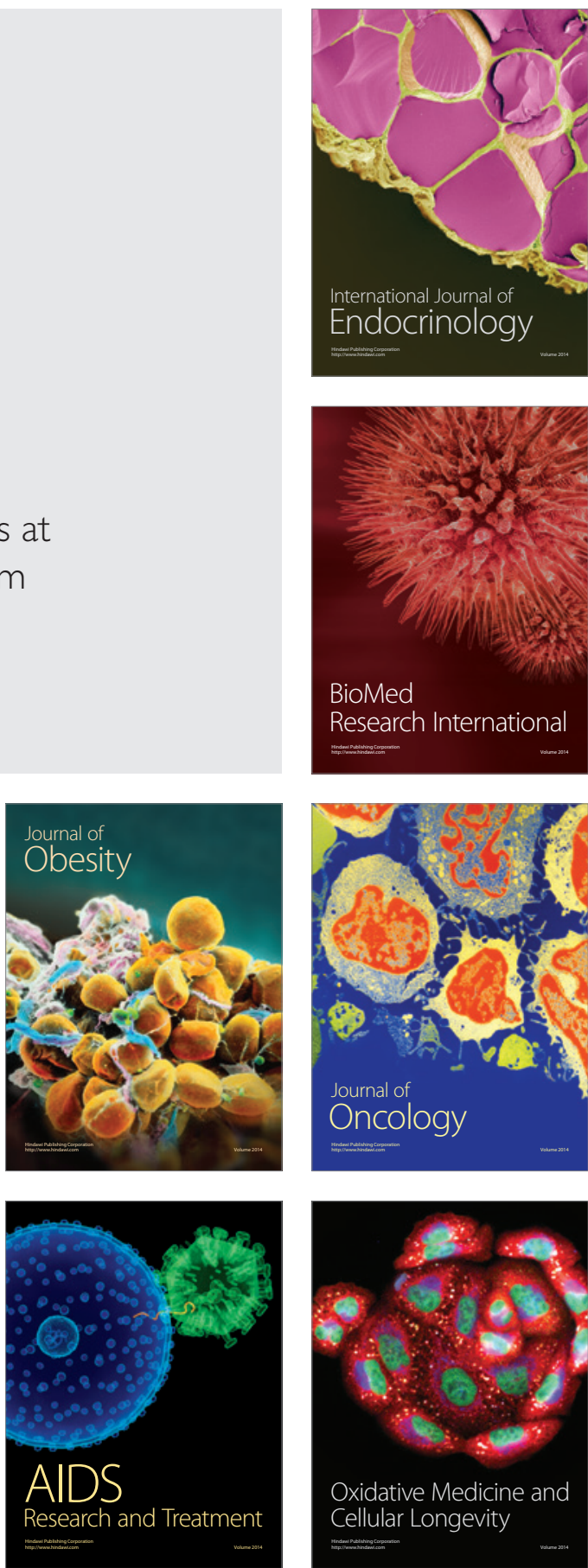